\title{
Susanna Bliggenstorfer, Eustache Deschamps. Aspects poétiques et satiriques
}

\section{Elena Peccia}

\section{Q OpenEdition}

10 Journals

\section{Édition électronique}

URL : https://journals.openedition.org/studifrancesi/25966

DOI : $10.4000 /$ studifrancesi.25966

ISSN : 2427-5856

Éditeur

Rosenberg \& Sellier

\section{Édition imprimée}

Date de publication : 1 avril 2007

Pagination : 150

ISSN : 0039-2944

\section{Référence électronique}

Elena Peccia, « Susanna Bliggenstorfer, Eustache Deschamps. Aspects poétiques et satiriques », Studi

Francesi [En ligne], 151 (LI | I) | 2007, mis en ligne le 30 novembre 2015, consulté le 23 novembre 2021. URL : http://journals.openedition.org/studifrancesi/25966 ; DOI : https://doi.org/10.4000/ studifrancesi.25966

Ce document a été généré automatiquement le 23 novembre 2021.

\section{(c)}

Studi Francesi è distribuita con Licenza Creative Commons Attribuzione - Non commerciale - Non opere derivate 4.0 Internazionale. 


\title{
Susanna Bliggenstorfer, Eustache Deschamps. Aspects poétiques et satiriques
}

\author{
Elena Peccia
}

\section{RÉFÉRENCE}

SUSANNA BLIGGENSTORFER, Eustache Deschamps. Aspects poétiques et satiriques, Tübingen und Basel, A. Francke Verlag («Romanica Helvetica», 125), 2005, pp. XVI-327.

1 L'ouvrage s'insère dans un courant récent de redécouverte d'Eustache Deschamps et il peut être considéré comme la première véritable monographie qu'on lui dédie. Il se concentre sur le thème de la satire chez Deschamps, en portant une attention spéciale au caractère innovant et expérimental de ses poésies. L'auteur fait remarquer en particulier comment Deschamps a transformé la pratique poétique de son temps par l'ouverture thématique des genres à forme fixe, qui ne sont plus réservés à la matière amoureuse, mais s'ouvrent à l'histoire, à la politique et à la vie quotidienne; surtout Deschamps est considéré innovant pour la subjectivité de sa poésie.

2 S. B. prend en examen essentiellement deux aspects: les objets d'une telle satire et ses procédés poétiques. Il faut rappeler cependant que «satire», au temps de Deschamps, ne possédait pas le sens actuel, mais plutôt celui de critique de la société. Critique que Deschamps adresse à la cour, royaume d'hypocrisie, mensonge et dissimulation, et à la noblesse qui, oublieuse maintenant de l'idéal chevaleresque, est pénétrée par le désir d'apparaître et de s'enrichir. Le rire est seulement un moyen pour blâmer et donc pour corriger les défauts de la société.

3 Dans un chapitre introductif S. B. tente d'établir une définition possible de satire, à partir des travaux de Deschamps; ensuite le volume est composé de deux parties, divisées elles-mêmes en deux sections. La première partie, consacrée à l'analyse des textes, s'articule en une première section dans laquelle on aborde le thème de la vie de 
cour et en une deuxième où on analyse la critique de la noblesse. Dans la deuxième partie, en deux sections également, sont étudiés les procédés poétiques de la satire de Deschamps, en prenant tout d'abord en examen les formes poétiques et leur fonction satirique, puis quelques procédés particuliers, servant à dissimuler le discours satirique, comme l'allégorie et la métaphore, les proverbes et les locutions.

Devant l'ampleur de la production poétique d'Eustache Deschamps, l'auteur préfère se concentrer, à titre d'exemple, sur l'analyse détaillée de deux lais: Le Lay de franchise, à caractère anticurial, et Le Lay de Vaillance, critiquant la noblesse, en faisant toutefois des allusions aux autres textes, chansons royales et ballades, qui abordent les mêmes thèmes.

5 Le volume est complété par un riche appendice qui présente l'édition des deux lais et de dix-sept autres poésies précédemment analysées; par des tableaux synoptiques, qui permettent une comparaison rapide sur les formes lyriques des ballades et des chansons royales et enfin par un index très utile contenant les pièces et les manuscrits cités, les thèmes traités, les noms propres de même que les locutions et les proverbes. Une bibliographie exhaustive conclut le volume. 